\title{
Incidence of dementia in older adults with Intellectual Disabilities
}

*Andre Strydom

Trevor Chan

Michael King

Angela Hassiotis

Gill Livingston

${ }^{*}$ Corresponding Author

Address for Drs Strydom, Livingston, Hassiotis and King:

UCL Mental Health Sciences Unit

Charles Bell House, 2nd Floor,

67-73 Riding House Street

London W1W 7EJ

$\mathrm{T}:+44(0) 2076799308$

F: $+44(0) 2076799426$

Address for Dr Chan:

Greenwich Community Learning Disability Team

Oxleas NHS Foundation Trust

Civic House

20 Grand Depot Road

London SE18 6SJ

Acknowledgements and declaration of interests:

The initial stages of the study was funded by the MRC through a Research

Fellowship to Andre Strydom (G106/1160). The research was supported by the R\&D departments of Oxleas NHS Foundation Trust, Harrow Primary Care Trust (PCT), Enfield PCT, Islington PCT and Camden PCT, who all received a proportion of funding from the NHS Executive; the views expressed in this publication are those of the authors and not necessarily those of the funders or the NHS Executive. Cormac Fenton and Rebekah Craig assisted with data collection during follow-up. We thank all the participants and their carers, and local area clinicians and social services staff involved in this study. 
Abstract:

Dementia may be more common in older adults with intellectual disability (ID) than in the general population. The increased risk for Alzheimer's disease in people with Down Syndrome (DS) is well established, but much less is known about dementia in adults with ID who do not have DS. We estimated incidence rates from a longitudinal study of dementia in older adults with ID without DS and compared them to general population rates. 222 participants with ID without DS aged 60 years and older were followed up an average of 2.9 years later to identify those who had declined in functional or cognitive abilities. Those who screened positive had a comprehensive assessment for dementia, diagnosed using ICD 10 and DSM IV criteria. 134 participants who did not have dementia at initial assessment were alive and interviewed at follow up; 21 (15.7\%) were diagnosed with dementia. Overall incidence rate for those aged $\geq 60$ was 54.6 / 1000 person years ( $95 \% \mathrm{Cl} 34.1-82.3$ ). The highest incidence rate (97.8/1000 person years) was in the age group 70-74. Standardised incidence ratio for those aged $\geq 65$ was 4.98 (95\% Cl $1.62-11.67)$. Incidence of dementia in older people with intellectual disabilities is up to five times higher than older adults in the general population. Screening may be useful in this population given the high incident rates, particularly as more effective treatments become available. Studies to explore the underlying aetiological factors for dementia associated with intellectual disability could help to identify novel protective and risk factors.

261 words 


\section{Background}

There have been several epidemiological studies of dementia in older adults with Down Syndrome (DS) which is known to be associated with an increased risk for Alzheimer's Disease (AD), but much less is known about dementia in the Intellectual Disability population who do not have Down Syndrome (non-DS ID)(Strydom, Shooshtari, et al., 2010).

Dementia may also be more common in adults with non-DS ID compared to the general population because of specific risk factors. ID is by definition associated with reduced brain reserve (i.e. smaller brain size, fewer neurons or synapse count) (Stern, 2002). The brain reserve hypothesis proposes that there is a critical threshold of reserve capacity that needs to be breached by pathological processes before clinical or functional symptoms will develop. Those with more reserve have been found to be less likely to develop dementia or cognitive decline (Valenzuela \& Sachdev, 2006; Whalley, Deary, Appleton, \& Starr, 2004). The brain reserve hypothesis therefore predicts that older adults with ID should have higher rates of dementia than those with normal intelligence, and that dementia rates will be relatively high in younger age groups because those with progressive brain pathology will quickly reach a functional cut-off with early emergence of symptoms (Strydom, Hassiotis, King, \& Livingston, 2009). Furthermore, several rare genetic ID syndromes are associated with progressive decline. However, older adults with ID may also be protected against dementia. For instance, they often have better cardiovascular risk profiles such as lower rates of smoking and ischaemic heart disease, which may reduce their risk for dementia, particularly vascular dementia (Haveman et al., 2010).

There have been a small number of dementia prevalence studies in the non-DS ID population, with several studies (Cooper, 1997; Shooshtari, Martens, Burchill, Dik, \& Naghipur, 2011; Strydom, Livingston, King, \& Hassiotis, 2007) showing an increased prevalence while some found rates similar to those in the general population (Zigman et al., 2004). We have previously shown that dementia prevalence varies by diagnostic criteria used, disability level and age (Strydom et al., 2009, 2007). Prevalence is also strongly influenced by mortality rates, and older adults with dementia have much higher mortality rates than those without dementia (Rait et al., 
2010). Prevalence rates may therefore underestimate a population's risk for dementia.

The present study reports the annual incidence of dementia in older adults with nonDS ID and compares it with population rates (standardised incidence ratio, SIR).

\section{Materials and Method}

This study reports on follow-up of the BOLD cohort which is described elsewhere (Strydom et al., 2009, 2007; Strydom, Romeo, et al., 2010). Appropriate ethics approval was obtained. Participants were any adults aged 60 years and older (mean age 68.8 years, SD 7.45; range 60 - 94) living in five London boroughs, who had ID of any aetiology except DS. ID was defined using ICD-10 criteria for mental retardation, and participants were identified by contacting all ID and ageing service providers within each borough. 222 participants participated in the baseline study (2004 -2005), of whom 33.3\% lived independently, in family homes or in settings without 24 hour support; $51.8 \%$ lived in community settings with 24 hour support, and $14.9 \%$ lived in hospitals or nursing homes. Informants were direct care staff, family or befrienders $(73.9 \%)$, home managers (12.6\%), nurses and other professionals $(8.1 \%)$ or day care staff $(4.5 \%)$. 28 met at least one of ICD-10, DSM-IV or DC-LD sets of dementia criteria. Participants were reassessed a mean of 2.9 years later $(S D=0.42$; 34.2 months, range 25 - 45 months) using a screen for dementia or cognitive decline; interviewers were blind to baseline assessments. Informants needed to have known the individual for at least the previous two years. If this was not possible, then the informants were asked to consult with others or to refer to case notes and care plans before completing the rating.

Those screened positive had a full diagnostic assessment for dementia.

\subsection{Screening and assessment}

The dementia screening procedure was similar at both time points (T1 and T2).

Screen positives were those who scored at or above the threshold for dementia for severe, mild-moderate and mild ID on the cognitive scale of the Dementia Questionnaire for Persons with Mental Retardation (DMR) (Evenhuis, 1996); decline in more than three aspects of activities of daily living on an adapted activities of daily living (ADL) schedule not accounted for by physical health issues; or a delayed recall after ten minutes of fewer than two items in a 3-item memory task based on the Shoe 
Box Test (Burt \& Aylward, 2000). Those screening negative were presumed not to have dementia.

Informants completed a questionnaire based on the Cambridge Mental Disorders Examination (CAMDEX), in order to determine whether participants who screened positive had symptoms of dementia (Roth et al., 1986). Participants who were sufficiently able also completed cognitive assessments described elsewhere (Jamieson-Craig, Scior, Chan, Fenton, \& Strydom, 2010; Strydom et al., 2007). These included the Test for Severe Impairment (Albert \& Cohen, 1992), Mini Mental State Examination (Folstein, Robins, \& Helzer, 1983) and the Tower of London test (Shallice, 1982). A structured physical examination was conducted to record neurological symptoms and signs associated with dementia and to identify thyroid disorder, stroke, Parkinson's disease and other physical disorders relevant to the differential diagnosis of dementia.

\subsection{Diagnosis}

Diagnostic procedures and reliability and validity of diagnoses are described in detail in other reports (Strydom et al., 2012, 2009, 2007). At baseline, independent diagnosis of dementia was made by two psychiatrists using an operationalized criteria tick list according to international operationalized dementia criteria. Disagreements were discussed with a third psychiatrist to reach a consensus decision. For the purpose of the incidence study, we defined dementia cases at baseline as all the participants who satisfied at least one of these criteria i.e. ICD-10 (World Health Organization, 1992), DSM-IV-TR (American Psychiatric Association, 2000), Dementia with Lewy bodies (McKeith et al., 2005) and frontotemporal dementia criteria (McKhann et al., 2001). All baseline dementia cases were excluded from the incidence calculation.

At follow up, ICD10 and DSM IV dementia criteria were used to define cases. Independent diagnosis of dementia was once again made by two psychiatrists and disagreements were discussed with a third psychiatrist to reach a consensus decision. These disagreements as well as the final decision in ratings were recorded and subsequent analysis showed that inter-rater reliability was very good or nearperfect (Strydom et al., 2012). 


\subsection{Analysis}

SPSS (v14) was used for this analysis. Incidence rates were calculated per 1000 person years, with $95 \%$ confidence intervals $(\mathrm{Cl})$ using binomial statistics. We used general population dementia rates from the MRC Cognitive Function and Ageing Studies (MRC-CFAS) (Matthews, Brayne, \& Medical Research Council Cognitive Function and Ageing Study Investigators, 2005) for comparison, as this was the largest and most recent incidence study of dementia in England and allowed comparisons by age and sex. The MRC-CFAS included several urban and rural locations, and used the Geriatric Mental State/ AGECAT system which allows ICD10, DSMIIIR or DSMIV dementia diagnoses. The MRC-CFAS dementia diagnoses were equivalent to DSMIIIR diagnoses (Matthews et al, 2005).

Age adjusted rates for those aged 65 and older were provided by the indirect method using reference rates in 5 year age bands from the MRC-CFAS and summed to calculate an age adjusted standardised incidence ratio (SIR). $95 \% \mathrm{CI}$ of the SIR was calculated using Poisson statistics.

To examine the impact mortality rates may have had on overall incidence rates, we conducted a sensitivity analysis by assuming that had all deceased participants lived, they would have had the same prevalence of dementia we observed in the baseline study stratified by age group (Strydom et al., 2007).

\section{Results}

One person was not included in this analysis as we were not able to gain enough information at T2 to determine his/her dementia status. 134/ 193 (69\%) of those without dementia at T1 participated and were included in the T2 incidence analysis; $29(15 \%)$ had died, and $30(15.5 \%)$ dropped out. 21 (15.7\%) new cases of dementia was diagnosed at T2 meeting either ICD $10(n=14)$ or DSM IV dementia criteria $(n=16)$ (table 1). There was a trend for those with incident dementia to be older than those without dementia (72.1 years; $s d=6.3$; vs. 69.5 years; $s d=5.8 ; t=-1.896 ; p$ $=0.06)$ there were no significant differences by $\operatorname{sex}\left(x^{2}=; d f=1 ; p=0.467\right)$ or severity of ID $\left(X^{2}=4.535 ; d f=2 ; p=0.104\right)$.

Table 1 shows incident rates by age group and overall rates. In order to allow comparison with general population rates from CFAS, the analysis was restricted to 
those aged 65 and over. The resulting SIR of the observed incidence rates compared to the general population rates was $4.98(95 \% \mathrm{Cl} 1.62-11.67)$.

Incidence rates in older people with ID peaked at 70-74 (see table 1). Overall rates for men aged 60 and older was higher than for women, but this difference was not significant (men, 64.9 / 1000 person years; 95\% Cl 35.0 - 108.4 vs. women 43.5/ 1000 person years; $95 \% \mathrm{Cl} 19.0-83.9$ ).

Sensitivity analyses did not reveal significant effect of mortality upon overall rates, but had the biggest effect on incidence rates in the oldest age groups (see table 1).

[Table 1 near here]

\section{Discussion:}

We found an incidence of dementia in adults with ID aged 65 and older which is up to five times higher than in the general population. Incidence peaked at age $70-74$, in contrast to a steady increase in the general population even beyond 90 years (Corrada, Brookmeyer, Paganini-Hill, Berlau, \& Kawas, 2010). We did not find higher rates in women, which differs from dementia incidence studies in the general population (Van der Flier, 2005).

\subsection{Strengths and limitations}

We undertook detailed assessments of screen positives and assigned dementia status using rigorous diagnostic procedures. We took a conservative approach by excluding all dementia cases at baseline (including those who met subtype criteria for Lewy body dementia and frontotemporal dementia) while using only DSM IV and ICD10 criteria to define incident cases. However, as no screening strategy for dementia in the ID population is completely robust, we may have missed some participants with incident dementia; thereby underestimating incidence. Furthermore, our previous work has shown diagnostic issues may affect estimates of dementia in this population, though these were as likely to result in under, as over, estimates (Strydom et al., 2012, 2007). Nevertheless, ICD10 and DSM IV diagnoses showed substantial inter-rater reliability $(\kappa>0.68)$ and had high specificity $(\sim 95 \%)$ (Strydom et al., 2012). 
When stratified by age bands or by sex, incidence rates had wide confidence intervals and we may therefore have missed smaller age or sex effects, but this remains the largest study of dementia incidence in older adults with ID (without Down syndrome) to date. Our findings are in keeping with previously reported increased prevalence rates of dementia in older adults with ID, but high mortality rates in older adults with ID and dementia could have affected rates as the excess incidence rates compared to the general population are even higher than the excess prevalence rates (Strydom et al., 2007) suggesting that people with ID and dementia have shorter survival than those in the general population.

\subsection{Implications}

This study confirms that older adults with non-DS ID are a high risk group for dementia. Incidence rates were considerably higher than general population rates, but not as high as the rates for people with Down syndrome. The increased risk for Alzheimer's Disease (AD) in Down Syndrome is believed to be due to triplication of genes on chromosome 21, including Amyloid Precursor Protein (APP) gene which is strongly implicated in AD (Vilardell et al., 2011). Our results are in keeping with the possibility that other genetic factors involved in brain development, learning and memory may be associated with neurodegeneration in later life. Recent examples include neurodegeneration associated with Kleefstra syndrome (Verhoeven, Egger, Vermeulen, Van de Warrenburg, \& Kleefstra, 2011), and a mutation affecting sodium/proton exchanger SLC9A6 which causes severe ID and tau deposition (Garbern et al., 2010), as well as the discovery of a Fragile X-associated tremor/ataxia syndrome that often presents with progressive decline (Hagerman \& Hagerman, 2004).

It is also possible that the increased likelihood to present with symptoms of dementia may, at least in part, be related to the reduced brain reserve associated with intellectual disability. The brain reserve hypothesis holds that reduced brain reserve should increase vulnerability to neuropathology in later life, and our findings are in keeping with this hypothesis. There may also be environmental effects that are important - many people with ID are not engaged in protective cognitively stimulating activities (such as education or meaningful occupation) to the same extent as their peers in the general population. Research to identify the underlying aetiology and risk factors for dementia in this population may therefore help to understand the 
aetiology of dementia in general - for example, by contrasting and comparing genetic and environmental factors associated with dementia in the Down Syndrome population to those in the non-DS ID population. This may reveal important risk and protective factors.

Our findings have important clinical implications. Current guidance does not support population screening for dementia in the UK or in the USA (National Collaborating Centre for Mental Health, 2007; Strydom, Shooshtari, et al., 2010). However, screening may be useful in older people with ID (even without DS) given the high incidence rates, particularly as their life expectancy increases and more effective treatments become available. Lack of recognition may delay provision of extra help or result in excess treatment with antipsychotics which increase morbidity and mortality (Gill et al., 2007; Treloar et al., 2010). Further research is therefore required to develop accurate screening strategies and to explore strategies for early diagnosis in this population.

\section{Conclusion}

Incidence of Dementia defined with DSMIV or ICD10 criteria is increased in older adults with Intellectual disability. Overall incidence rate for those aged $\geq 60$ was 54.6/ 1000 person years $(95 \% \mathrm{Cl} 34.1$ - 82.3) and the standardised incidence ratio for those aged $\geq 65$ was $4.98(95 \% \mathrm{Cl} 1.62-11.67)$; dementia incidence is thus up to 5 times higher than in the general population. Mortality-adjusted rates increased from 24/1000 person-years in those aged 60-64 to 97.8/1000 person-years in those aged 70-74. There were no gender differences in dementia incidence rates. Screening to identify those with cognitive decline may be useful in older people with ID, even those without Down Syndrome, particularly as their life expectancy increases and more effective treatments become available, and further research is needed to explore aetiological factors associated with increased risk for dementia in the non-DS ID population. 


\section{References:}

Albert, M., \& Cohen, C. (1992). The Test for Severe Impairment: an instrument for the assessment of patients with severe cognitive dysfunction. Journal of the American Geriatrics Society, 40(5), 449-453.

American Psychiatric Association. (2000). Diagnostic and Statistical Manual of Mental Disorders DSM-IV-TR Fourth Edition (4th ed.). American Psychiatric Association.

Burt, D. B., \& Aylward, E. H. (2000). Test battery for the diagnosis of dementia in individuals with intellectual disability. Working Group for the Establishment of Criteria for the Diagnosis of Dementia in Individuals with Intellectual Disability. Journal of Intellectual Disability Research: JIDR, 44 ( Pt 2), 175-180.

Cooper, S.-A. (1997). High Prevalence of Dementia Among People with Learning Disabilities Not Attributable to Down's Syndrome. Psychological Medicine, 27(03), 609-616.

Corrada, M. M., Brookmeyer, R., Paganini-Hill, A., Berlau, D., \& Kawas, C. H. (2010). Dementia incidence continues to increase with age in the oldest old: the $90_{+}$ study. Annals of Neurology, 67(1), 114-121.

Evenhuis, H. M. (1996). Further evaluation of the Dementia Questionnaire for Persons with Mental Retardation (DMR). Journal of Intellectual Disability Research, 40(4), 369-373.

Folstein, M. F., Robins, L. N., \& Helzer, J. E. (1983). The Mini-Mental State Examination. Arch Gen Psychiatry, 40(7), 812.

Garbern, J. Y., Neumann, M., Trojanowski, J. Q., Lee, V. M.-Y., Feldman, G., Norris, J. W., Friez, M. J., et al. (2010). A mutation affecting the sodium/proton exchanger, SLC9A6, causes mental retardation with tau deposition. Brain: a journal of neurology, 133(Pt 5), 1391-1402. 
Gill, S. S., Bronskill, S. E., Normand, S.-L. T., Anderson, G. M., Sykora, K., Lam, K., Bell, C. M., et al. (2007). Antipsychotic Drug Use and Mortality in Older Adults with Dementia. Annals of Internal Medicine, 146(11), 775 -786.

Hagerman, P. J., \& Hagerman, R. J. (2004). Fragile X-associated tremor/ataxia syndrome (FXTAS). Mental Retardation and Developmental Disabilities Research Reviews, 10(1), 25-30.

Haveman, M., Heller, T., Lee, L., Maaskant, M., Shooshtari, S., \& Strydom, A. (2010). Major Health Risks in Aging Persons With Intellectual Disabilities: An Overview of Recent Studies. Journal of Policy and Practice in Intellectual Disabilities, 7(1), 59-69.

Jamieson-Craig, R., Scior, K., Chan, T., Fenton, C., \& Strydom, A. (2010). Reliance on Carer Reports of Early Symptoms of Dementia Among Adults With Intellectual Disabilities. Journal of Policy and Practice in Intellectual Disabilities, 7(1), 34-41.

Matthews, F., Brayne, C., \& Medical Research Council Cognitive Function and Ageing Study Investigators. (2005). The Incidence of Dementia in England and Wales: Findings from the Five Identical Sites of the MRC CFA Study. PLoS Med, 2(8), e193.

McKeith, I. G., Dickson, D. W., Lowe, J., Emre, M., O’Brien, J. T., Feldman, H., Cummings, J., et al. (2005). Diagnosis and management of dementia with Lewy bodies: third report of the DLB Consortium. Neurology, 65(12), 18631872.

McKhann, G. M., Albert, M. S., Grossman, M., Miller, B., Dickson, D., \& Trojanowski, J. Q. (2001). Clinical and pathological diagnosis of frontotemporal dementia: report of the Work Group on Frontotemporal Dementia and Pick's Disease. Archives of neurology, 58(11), 1803-1809.

National Collaborating Centre for Mental Health. (2007). Dementia: Supporting people with dementia and their carers in health and social care 
(Guidance/Clinical Guidelines No. Clinical guidelines, CG42). Retrieved from http://guidance.nice.org.uk/CG42

Rait, G., Walters, K., Bottomley, C., Petersen, I., Iliffe, S., \& Nazareth, I. (2010).

Survival of people with clinical diagnosis of dementia in primary care: cohort study. BMJ (Clinical Research Ed.), 341, c3584.

Roth, M., Tym, E., Mountjoy, C. Q., Huppert, F. A., Hendrie, H., Verma, S., \& Goddard, R. (1986). CAMDEX. A standardised instrument for the diagnosis of mental disorder in the elderly with special reference to the early detection of dementia. The British Journal of Psychiatry, 149(6), 698 -709.

Shallice, T. (1982). Specific impairments of planning. Philosophical Transactions of the Royal Society of London. Series B, Biological Sciences, 298(1089), 199209.

Shooshtari, S., Martens, P. J., Burchill, C. A., Dik, N., \& Naghipur, S. (2011). Prevalence of Depression and Dementia among Adults with Developmental Disabilities in Manitoba, Canada. International Journal of Family Medicine, 2011, 1-9.

Stern, Y. (2002). What Is Cognitive Reserve? Theory and Research Application of the Reserve Concept. Journal of the International Neuropsychological Society, 8(03), 448-460.

Strydom, A., Chan, T., Fenton, C., Craig, R., Livingston, G., \& Hassiotis, A. (2012). Validity of Criteria for Dementia in Older People With Intellectual Disability. The American Journal of Geriatric Psychiatry: Official Journal of the American Association for Geriatric Psychiatry.

Strydom, A., Hassiotis, A., King, M., \& Livingston, G. (2009). The Relationship of Dementia Prevalence in Older Adults with Intellectual Disability (ID) to Age and Severity of ID. Psychological Medicine, 39(01), 13-21. 
Strydom, A., Livingston, G., King, M., \& Hassiotis, A. (2007). Prevalence of dementia in intellectual disability using different diagnostic criteria. The British Journal of Psychiatry, 191(2), 150-157.

Strydom, A., Romeo, R., Perez-Achiaga, N., Livingston, G., King, M., Knapp, M., \& Hassiotis, A. (2010). Service use and cost of mental disorder in older adults with intellectual disability. The British Journal of Psychiatry, 196(2), 133-138.

Strydom, A., Shooshtari, S., Lee, L., Raykar, V., Torr, J., Tsiouris, J., Jokinen, N., et al. (2010). Dementia in Older Adults With Intellectual DisabilitiesEpidemiology, Presentation, and Diagnosis. Journal of Policy and Practice in Intellectual Disabilities, 7(2), 96-110.

Treloar, A., Crugel, M., Prasanna, A., Solomons, L., Fox, C., Paton, C., \& Katona, C. (2010). Ethical dilemmas: should antipsychotics ever be prescribed for people with dementia? The British Journal of Psychiatry, 197(2), 88 -90.

Valenzuela, M. J., \& Sachdev, P. (2006). Brain Reserve and Dementia: A Systematic Review. Psychological Medicine, 36(04), 441-454.

Van der Flier, W. M. (2005). Epidemiology and risk factors of dementia. Journal of Neurology, Neurosurgery \& Psychiatry, 76(suppl_5), v2-v7.

Verhoeven, W. M. A., Egger, J. I. M., Vermeulen, K., Van de Warrenburg, B. P. C., \& Kleefstra, T. (2011). Kleefstra syndrome in three adult patients: further delineation of the behavioral and neurological phenotype shows aspects of a neurodegenerative course. American journal of medical genetics. Part $A$, 155A(10), 2409-2415.

Vilardell, M., Rasche, A., Thormann, A., Maschke-Dutz, E., Pérez-Jurado, L. A., Lehrach, H., \& Herwig, R. (2011). Meta-analysis of heterogeneous Down Syndrome data reveals consistent genome-wide dosage effects related to neurological processes. BMC Genomics, 12(1), 229. 
Whalley, L. J., Deary, I. J., Appleton, C. L., \& Starr, J. M. (2004). Cognitive reserve and the neurobiology of cognitive aging. Ageing Research Reviews, 3(4), 369-382.

World Health Organization. (1992). The ICD-10 Classification of Mental and Behavioural Disorders: Clinical Descriptions and Diagnostic Guidelines (1st ed.). World Health Organization.

Zigman, W. B., Schupf, N., Devenny, D. A., Miezejeski, C., Ryan, R., Urv, T. K., Schubert, R., et al. (2004). Incidence and prevalence of dementia in elderly adults with mental retardation without down syndrome. American Journal of Mental Retardation: AJMR, 109(2), 126-141. 
Table 1: Observed and mortality adjusted incidence rates in 5 year age bands

* excluding tentative cases

\begin{tabular}{|c|c|c|c|c|c|c|c|c|}
\hline \multirow[t]{2}{*}{ Age } & \multirow{2}{*}{$\begin{array}{l}\text { Person years } \\
\text { of follow-up }\end{array}$} & \multicolumn{2}{|c|}{ ICD 10 dementia* } & \multicolumn{2}{|c|}{ DSM IV dementia } & \multicolumn{3}{|c|}{ Any dementia } \\
\hline & & $\begin{array}{l}\text { Cases } \\
(\%)\end{array}$ & $\begin{array}{l}\text { Rate per } 1000 \\
\text { person years } \\
(95 \% \mathrm{Cl})\end{array}$ & Cases (\%) & $\begin{array}{l}\text { Rate per } 1000 \\
\text { person years } \\
(95 \% \mathrm{Cl})\end{array}$ & $\begin{array}{l}\text { All Cases } \\
(\%)\end{array}$ & $\begin{array}{l}\text { Overall rate } \\
\text { per } 1000 \\
\text { person years } \\
(95 \% \mathrm{Cl})\end{array}$ & $\begin{array}{l}\text { Mortality adjusted } \\
\text { rates per } 1000 \\
\text { person years } \\
(95 \% \mathrm{Cl})\end{array}$ \\
\hline $60-64$ & 71.8 & $2(7.7)$ & $\begin{array}{l}27.9 \\
(3.4-97.0)\end{array}$ & $1(3.8)$ & $\begin{array}{l}13.9 \\
(0.4-75.2)\end{array}$ & $2(7.7)$ & $\begin{array}{l}27.9 \\
(3.4-97.0)\end{array}$ & $\begin{array}{l}24 \\
(7.0-78.7)\end{array}$ \\
\hline $65-69$ & 152.1 & $3(5.8)$ & $\begin{array}{l}19.7 \\
(4.1-56.6)\end{array}$ & $5(9.6)$ & $\begin{array}{l}32.9 \\
(10.8-75.0)\end{array}$ & $5(9.6)$ & $\begin{array}{l}32.9 \\
(10.8-75.0)\end{array}$ & $\begin{array}{l}31.8 \\
(13.3-68.6)\end{array}$ \\
\hline $70-74$ & 75.3 & 5 (19.2) & $\begin{array}{l}66.4 \\
(21.9-148.2)\end{array}$ & $6(23.1)$ & $\begin{array}{l}79.6 \\
(29.8-165.4)\end{array}$ & $9(34.6)$ & $\begin{array}{l}119.5 \\
(56.1-214.8)\end{array}$ & $\begin{array}{l}97.8 \\
(48.3-161.8)\end{array}$ \\
\hline $\begin{array}{l}75 \text { and } \\
\text { older }\end{array}$ & 85.2 & $4(13.3)$ & $\begin{array}{l}46.9 \\
(12.9-115.9)\end{array}$ & 4 (13.3) & $\begin{array}{l}46.9 \\
(12.9-115.9)\end{array}$ & $5(16.7)$ & $\begin{array}{l}58.2 \\
(19.3-131.7)\end{array}$ & $\begin{array}{l}71.0 \\
(31.5-125.3)\end{array}$ \\
\hline \multicolumn{9}{|l|}{ Overall: } \\
\hline $\begin{array}{l}\text { Aged } 60 \\
\text { and older }\end{array}$ & 384.3 & $\begin{array}{l}14 \\
(10.4)\end{array}$ & $\begin{array}{l}36.4 \\
(20.1-60.4)\end{array}$ & $16(11.9)$ & $\begin{array}{l}41.6 \\
(24.0-66.7)\end{array}$ & $21(15.7)$ & $\begin{array}{l}54.6 \\
(34.1-82.3)\end{array}$ & $\begin{array}{l}53.7 \\
(28.0-67.7)\end{array}$ \\
\hline $\begin{array}{l}\text { Aged } 65 \\
\text { and older }\end{array}$ & 312.5 & - & - & - & - & $19(17.3)$ & $\begin{array}{l}60.8 \\
(37.0-93.3)\end{array}$ & $\begin{array}{l}60.9 \\
(41.0-89.6)\end{array}$ \\
\hline
\end{tabular}

